European journal of American studies

$10-2$ | 2015

Summer 2015, including Special Issue: (Re)visioning

America in the Graphic Novel

State Protection and Identification in Hellboy: of
reformed devils and other Others in the Pentagon

Maaheen Ahmed

CpenEdition

Journals

Electronic version

URL: https://journals.openedition.org/ejas/10938

DOI: 10.4000/ejas. 10938

ISSN: 1991-9336

Publisher

European Association for American Studies

Electronic reference

Maaheen Ahmed, "State Protection and Identification in Hellboy: of reformed devils and other Others in the Pentagon", European journal of American studies [Online], 10-2 | 2015, document 6, Online since 14 August 2015, connection on 08 July 2021. URL: http://journals.openedition.org/ejas/10938 ; DOI: https://doi.org/10.4000/ejas.10938

This text was automatically generated on 8 July 2021

Creative Commons License 


\title{
State Protection and Identification in Hellboy: of reformed devils and other Others in the Pentagon
}

\author{
Maaheen Ahmed
}

Rasputin: "Think, creature! Think! If you kill me
you will never know WHO you are!"
Hellboy: "Yeah, you're right. But I can LIVE with
it!"
(Mignola and Byrne)

1 The words of the Russian occultist Rasputin, who is responsible for summoning Hellboy to earth, reappear only a few pages after the exchange above, this time as an ominous memory ending the first Hellboy book. They promise that there will be more to come while emphasizing the ambiguity of the protagonist's being. Acquiring a normal, human identity or even comprehending his origins remains an impossibility for Hellboy. The same holds for most of his friends who by virtue of their appearance and their superpowers are marked with the label of paranormal. While the pariah status is not unknown to superheroes, monstrous superheroes are rare. Even alternative heroes like the Sandman or the Swamp Thing, in their varying embodiments, were once human. This also holds for the more classic, Silver Age superheroes like Hulk and Fantastic Four's The Thing (who are, like Hellboy, monsters fighting evil). Hellboy, in contrast, is a demon choosing to fight on the side of the good. He is originally incorporated into the US defense system by virtue of being a member of the Bureau of Paranormal Research and Defense (BPRD), which in the fictional world of the series is a part of the Pentagon. Rasputin's words underscore the importance of knowing the enemy, the Other who is essential for defining the self. However Hellboy's identity is based on negating the demon he was destined to be. This in turn demonstrates the possibility of choosing and molding oneself and one's life (an aspect that is pushed to the forefront in the first Hellboy movie); it is also emblematic of the valorization of the individual and the endless possibilities America once offered, consequently attracting 
immigrants who were marginalized in their countries of birth or who simply sought a better life.

2 Yet Hellboy has several twists, not only due to Hellboy's original abode in hell but also his abnormality, which is uncomfortably combined with his indispensability for the US government in its fight against the forces of darkness. Facing both regular human armies and spiritual, ancient ones with supernatural powers, the State is forced to turn to unusual solutions like Hellboy. The series' fantastic reconceptualization of the image of the US government as well as its use of religious, mythical and historical symbols of fear, not only forms a fertile plane for adventures along the good-evil axis, but also calls for a reconsideration of unusual beings, outcasts or simply Others in the vein of $X-M e n$, thus updating its allusions to the civil rights movement to the contemporary context. It is my argument that Hellboy also offers a fertile ground for analyzing notions of identity, integration and State security in the American context, albeit allusively rather than directly owing to the series' fantastic nature. Indeed it has already been the subject of readings attuned to its embedding of sociopolitical imaginaries; the diversity of these readings indicate the series' ability to allude to a broad range of issues (Sommers; O'Connor; Vinci).

3 Early in his article on the conceptualization of American identity and territory in recent Captain America volumes, political geographer Jason Dittmer points out how individual and collective nationalistic identities are concretized through cultural and sociopolitical factors:

Marston and Smith (2001) have made the point that collective identity formation involves the negotiation of many different scales, including the full continuum from the individual/ body to the global/universal. Thus, the horizontal identity issues that revolve around the Self/Other nexus and other boundary-formation processes [...] are inextricably linked through geopolitical narratives to vertical issues of scale. This is a critical link that enables hundreds of millions of individuals freely to assume a common identity. (Dittmer 626).

It is owing to the vertical axis of scale of globalization which leads to a shared, uniform consumer culture that it possible for Hellboy to become, at least to a certain extent, American. As Dittmer points out, popular culture products not only trace these identity formations but their consumption also "leads to the internalization of the mythic and symbolic aspects of national identities" (ibid.). In this sense, Hellboy's demonic appearance and acculturation alludes to immigrants who can never, on grounds of their appearance, be fully integrated in America.

5 As a creature assimilated into humanity and, more specifically, American culture, Hellboy also negotiates the binaries of self and Other by adopting American principles and values. However this is an uneasy reconciliation because of his monstrous essence, and is one of the reasons behind his quitting the BPRD at the end of the fifth volume (The Conqueror Worm, 2001), to venture into spaces that become increasingly fantastic until he dies in the series' final issue, The Storm and the Fury.

6 Following Dittmer, I will explore three ways of considering comic book heroes as indicators of individual and collective identity formation with reference to their contexts of production. Hellboy's overt celebration of monstrosity and strangeness suggests the series may be read:

1. As a reflection of and on the vagueness surrounding contemporary American identity on the level of the individual; 
2. As a reflection of post-9/11 collective American identity, defensiveness, and xenophobia;

3. And as a subversion, typical for the comics medium (see Smolderen, 2009; Bukatman, 2012) of the blatant binaries involved in collective identity formation and xenophobia.

7 The series and its franchise acts out issues of identity and defense on the level of themes and images without necessarily defining them. Its comments, in other words, unfold through allusions. In this respect the sublimating role of fantasy, one of the main genres Hellboy can claim allegiance to, will also be considered. In order to consider the series' interaction with sociopolitical and comics imaginaries, Hellboy as well as other monstrous comics protagonists, their constructions of identity and their relations with the US government will now be considered.

\section{Monstrosity of superheroes - possible implications}

8 Hellboy or Anung un Rama is far from being the first monstrous superhero with a dark past-Hulk and the X-Men appeared decades ago and Spawn, another former denizen of Hell, only a year before Hellboy. (It is thus noteworthy that Mignola engaged John Byrne, who had worked on Hulk and X-Men, for writing the earlier Hellboy volumes.) An ex-demon with a grudge against Rasputin and the Nazis who summoned him in 1944 as a supernatural weapon of mass destruction, Hellboy was raised by the eventual head of the BPRD, Trevor Bruttenholm, and grew up as an uncomfortable conglomeration of self and otherness, enemy and friend. This awkwardness increases when situated within the context of a globalized world of fluid identities and spaces on one hand and the not-so-smooth reality of a multicultural America on the other. And tellingly enough, Hellboy made his first appearance in the one-page advertisement entitled Celebrate Diversity (1994, Diamond Comics Distributors). Hellboy invites reflection on immigration; it can also be seen as making significant comments regarding the nature of the enemy as well as those defending and protecting the State. The enemy in Hellboy's story world is a coalition of well-preserved Nazis and a malevolent monk, but - as is often the case in the superhero genre - is also a representative of mythical Evil warring against Good, as well as the representative of real-world sociopolitical antagonists.

9 In Celebrate Diversity, Hellboy introduces himself by showing his baby picture with the US Army during World War II, and mentioning that he was given honorary human status by a special act passed by the United Nations in 1952, which led to his becoming part of the BPRD. This affiliation with the US government sets him apart from the vigilantes so familiar from superhero comic books. Moreover, in contrast to the few superheroes openly working for the State such as Captain America, Hellboy has one major problem: his demonic appearance and essence. From the BPRD - comprised of Liz, who apart from her pyrokinesis is human, Abe the "ichthyo sapien," Roger the homunculus and the disembodied Johann Straus - Hellboy is the only one who is completely non-human. Possibly by virtue of having monstrous attributes, and his consequent proximity to demonic villains, Hellboy and his companions are secretly embedded in the State's structure in a department dedicated to defending against supernatural attacks. The use of monsters in the defense system also alludes to the transformation of soldiers into killing machines divorced from their humanity. 
However all the members of the BPRD also need protection from the real world, which is provided through the BPRD's direct but secret incorporation into the State's defense organ. Although superheroes from other comics are not always employed by the government, their very existence and defense mechanisms often have close links with the US army's research and development (even the Dark Knight, Batman, relies on tools and techniques used by the CIA and the military). Indeed, America's superheroes regularly play significant roles in crisis management in their fictional worlds. Even within the Hellboy world, there is The Torch of Liberty, a Golden Age superhero, who is with the US army at the time Hellboy is summoned to Earth. Moreover Hellboy grows up on comics adventures of the more ordinary but equally efficient vigilante, Lobster Johnson, who dies in The Conqueror Worm while saving another BPRD agent. Briefly successful during the late 1930 s and the 40 s, he is, as Hellboy is emphatically told by a government official, nonexistent as far as the US government is concerned. Having the precedents of earlier superheroes like the Torch of Liberty and Lobster Johnson, Hellboy is placed almost on par with his readers who also have two generations of comic book heroes behind them. However he also echoes "[...]in part the history of American comics, and the pulp heroes that preceded them" (Weiner et al. 12) through his character as well as through the stories he gets involved in.

10Correlating social changes contributing to new identity constructions with the characterization of comics heroes, Robert Genter illustrates how the unease emerging with the shift from blue-collar to white-collar workers during post-industrialization is reflected through Bruce Banner's conformism and his alter-ego Hulk who represents the earlier, more common man of action (Genter 963). Most superheroes reflect the manliness of the blue-collar American worker defined by brute force, which Hellboy, having no alter-ego, fully incorporates. Nonetheless he also imbibes the psychological issues or even trauma ushered in by the transformed, more conformist and less physical, white-collar role of men in post-industrial America, with superheroes of the Silver Age like Bruce Banner-Hulkand Peter Parker-Spider Man providing models that a new generation of non-conformist readers living under the threat of mass destruction could identify with:

...to youth fighting a cultural and political war against "the one-dimensional man" of the Cold War order, the alienated but confident heroes of Marvel comics served as emblems of an authentic subjectivity deemed lost, expressing the existential anguish of a generation growing up under the threat of nuclear catastrophe. (Genter 974).

11 Unlike most superheroes, who are often the outcomes of willed or unwilled scientific experiments (Captain America, Hulk, the Fantastic Four), Hellboy was summoned by enemy forces to bring about the end of the world. Neither man-made nor an accident of science and technology, Hellboy embodies the inexplicable older forces that go beyond man and his world, consequently displacing an anthropocentric universe to a Lovecraftian void, where man's world forms only a tiny part of a massive, unfathomable whole. Comparable to the Thing and the Hulk or many of the monstrous heroes of the comics' universe, Hellboy also merges extreme power with primitivism, irrationality and subsequent unpredictability. Yet in his case the unpredictability is mostly a part of others' perception of him instead of being grounded in fact. Despite being tested time and again, called by various powers to fulfill his destiny and usher in the end of the world (usually indicated by the adoption of a more beastlike posture and the growing of his horns, which he is careful to file down), Hellboy never succumbs to 
the demonic, thereby demonstrating a reliability that contrasts with his monstrous appearance and underscores the inaccuracy of stereotypical constructions and perceptions of others on the basis of external appearance.

12Stephen Weiner asserts that Hellboy "speaks to us symbolically, isolating our fears and hopes so that we can wrestle with them from a safe distance" (Weiner et al. 12, also cited by Vinci 1041). Yet this symbolism is almost too direct. It is little more than the anti-hero visualized through his monstrous appearance, the bad boy cliché, clothed in an externally inhuman but internally human form. This bad boy figure is especially recurrent in American popular culture, on the sides of both good (Bruce Wayne) and evil (Mafioso). Weiner himself mentions Hellboy's affiliations with the pulp detective heroes (Weiner et al. 12). This however is not new in itself, for already Superman shared similarities with contemporaneous pop culture heroes like Dick Tracy and the Lone Ranger (Lund 88). It is the outcome of the amalgamating, or what Chris Murray sees as the cannibalistic, tendency of the superhero genre, which in itself is a hybrid of adventure, fantasy, crime and other genres (Murray 2) and also exemplifies the possibly excessive juxtaposition and appropriation of diverse elements recurrent in popular culture. Hence Joseph Michael Sommers sees Hellboy as "a construction that centers on an idea of examining the interstitial narratives formed in an interplay of history, religion, mythology, and other discourses through the lens of popular narratives" (Sommers 219). This interplay of history, religion and the mythologies of several cultures also levels out the credibility and values associated with these disparate discourses and reveals their malleability, in turn acquiring relevance for a postmodern, globalized milieu based on the rapid exchange of information and people as well as the easy fabrication of truths and realities. To construe this interaction of fiction and popular culture with sociopolitical factors, it is necessary to elaborate upon Hellboy's identity and citizenship.

\section{Hellboy's Americanness}

13 According to Weiner, "Hellboy's response to danger is decidedly American - a wisecrack followed by a powerhouse right..." which is common for many superheroes but is traced by Weiner to the American detective pulps from the 1920s and 30s (Weiner et al. 12) as well as to Robert Howard's Conan the Barbarian, one of the earliest of the socalled sword and sorcery or heroic fantasy heroes (Weiner et al. 209). Born or called to earth in the ruins of a cathedral in the fictional English town of East Bromwich (the event being narrated by a disbelieving American sergeant, whose deprecating sense of humor echoes Hellboy's attitude along with that of many comic book heroes from Corto Maltese to Iron Man), Hellboy seems destined for the New World. His battles are consequently with the older world order, the ancient, inconceivably powerful supernatural forces populating the folklore of several regions, including Russia, Britain, Greece and Egypt. Yet villains in the early Hellboy volumes are the stereotypical bad guys populating American popular culture - Nazis, Eastern Europeans and Russians, who are nonetheless molded by a massive dose of fantasy and accompanied by a rich variety of folklore, a fusion of popular Western and Eastern myths reflecting the interaction, coexistence and even homogenization of diverse cultures facilitated by globalization. Yet although the main battles of the earlier volumes are against 
resurrected Nazis, in the later volumes it is the Christian story of the Apocalypse, which Hellboy is destined to usher in, that takes over.

14Hellboy became partly human through his acculturation, beginning with the Baby Ruth candy bar his adoptive father Trevor Bruttenholm used to make friends with him (in the first Hellboy movie) and continuing with the pancakes a certain General Norton Ricker of the BPRD feeds him for breakfast, with a fork branded with the initials of the USA (in the fourth volume, The Right Hand of Doom). Unlike the majority of superheroes, Hellboy does not have the option of disguising himself as another ordinary citizen.As American as he may be through fully embracing American popular culture and food, he always remains a glaringly obvious outsider.

15 Yet it is not just what can be likened to the (legal) immigrant's dilemma that comes into play but the problem of a somewhat relative identity construction or selfdefinition, which is necessarily dependent on others. Hellboy's own Americanness is underscored by the contrast provided by the multicultural, or even transcultural, entourage of "freaks" (a word which itself has an old tie with the popular entertainment industry), most of whom have openly foreign mannerisms and tastes. It is therefore vis-à-vis these other Others that he can be said to have considerable claim over Americanness in terms of mindset and spirit. The juxtaposition to the other members of the group highlights his very American mentality of being extroverted, straightforward, and hard-working which, as Vinci points out, is propelled by his unwanted destiny of ushering in doom: "Hellboy is an unlikely hero. A demon destined to be the beast of the apocalypse, he avoids this fate by embracing working-class mediocrity" (Vinci 1051). In concentrating on the fourth Hellboy volume, The Right Hand of Doom, Laura O'Connor makes a similar point regarding Hellboy's incorporation of the working class mentality, or what Max Weber identified as the protestant work ethic, which played a crucial role in the American economic and social system:

Hellboy speaks, behaves, and is treated like the regular Joe he likes to believe he is, but as he confesses in Right Hand of Doom, he survives by "never deal[ing] with what I am ... I just do my job, which usually involves me beating the crap out of things a lot like me" (Epilogue, 2). (O'Connor 553).

16 As Vinci elaborates, "[w]hat makes Hellboy heroic is not his worldview, lifestyle, or even his actions-what makes him heroic is his choice not to be evil... This is allegorized through his physical confrontations with monsters that serve as repeated reminders of his destiny" (Vinci 1052). Such an act of rebelling against supposedly prescribed destinies, physically and metaphorically combating one's own demons, trying to identify and belong is something most readers would be familiar with (and indeed comics themselves are replete with identity crises). This brings out Hellboy's inherent and extensible identification potential, not in spite of, but actually because of his otherness and his consequent embrace of the familiar, working-class, American mentality. Furthermore Hellboy's situation can also be taken as commenting on the construction or cementing of nationalism in opposition to other, necessarily evil forces, with saving the State becoming synonymous with saving the world. In the nationalistic drive to combat Evil, the more benign or friendlier others are assimilated, but always only to a certain degree, which varies with changing sociopolitical conditions.

17 However his very existence and his job, combating the supernatural - or paranormal as it is officially and somewhat unsettlingly called - also shows how vague, fluid and easily permeable the country's boundaries are. America's territorial 
demarcation and its persistent infiltration by the paranormal dimension in Hellboy mirrors the influx of both legal and illegal immigrants unsettling, if not dissolving, the concept of a unified, homogenous American identity.

\section{Immigration and American identity}

18Civic nationalism, the law of jus soli, ties American identity with the land, with the act of settling there but without the need of having lived there for generations. America has been, and still is, the land of not only immigrants but also immigration. This necessitated the creation of a new, collective identity, for which the image of the melting pot was used as early as the $18^{\text {th }}$ century by Hector St. John de Crevecoeur and continues to prevail even today: "He becomes an American by being received in the broad lap of our Alma Mater. Here individuals of all nations are melted into a new race of men..." (Crevecoeur cited by Lund 85). In his subsequent elaboration of the melting pot concept, Lund's emphasis on culture and ideals is noteworthy. Americans were to share aspirations, principles and ways of life, and it was through their common ideals that they became Americans:

Just as individuals were expected to "melt" into America in Crevecoeur's time, so too were they accepted into the American "Melting Pot" only on the condition that they accepted the mores and ideals of white America in the decades and centuries that followed. Foreign cultures and ideals were to be checked at Ellis Island, as it were, and people coming from all over the world were to become a homogenous whole, a country of Americans in race, creed, and culture, through assimilation and acculturation. (Lund 85).

Quoting the psychologist Erik H. Erikson, Peter Freese highlights the problems the melting pot ideal could create through its desire "to make a super-identity out of all the identities imported by its constituent immigrants," which, as the current difficulty in assimilating the large group of Hispanic immigrants indicates, is far from easy (Freese). Yet America's existence, identity building and ascension to world superpower was never seen as being easy. Citing the Yale inauguration address of John Trumbull from 1770 below, John M. Murrin is careful to point out Trumbull's exultation of the necessary violence in America's passage towards greatness in all fields, leading to the appropriation of Britain's role as the world's superpower:

See where her Heroes mark their glorious way,

Arm'd for the fight and blazing on the day

Blood stains their steps; and o'er the conquering plain,

'Mid fighting thousands and 'mid thousands slain,

Their eager swords promiscuous carnage blend,

And ghastly deaths their raging course attend.

Her mighty pow'r the subject world shall see;

For laurel'd Conquest waits her high decree. (Trumbull cited by Murrin).

20 Hellboy, like a good soldier, regularly participates in similar carnage, but at the very end of the series he loses himself to the powers of Evil he has fought against. Nevertheless, in sacrificing himself in order to prevent the total destruction of the world, he also contributes to the war memory playing, as Susan-Mary Grant points out, a major role in the construction of American national identity and its unification, reinforced by the post-9/11 surge of nationalism. This is where the first two paths for interpreting Hellboy as expressing contemporary individual and contemporary 
American identity issues, somewhat vaguely positioned with reference to Others and the need to defend the country (both land and people) against those Others, converge.

\section{Post-9/11 and the renewal of fantasy}

21 In her discussion of "The Corpse" tale (from the third Hellboy volume, The Chained Coffin and Other Stories), O'Connor provides an apt contextualization of Hellboy in the post- 9/11 world:

In the home-security panics and state-of-war since $9 / 11$, the legendary superhero cuts a reassuring figure. He embodies a fantasy of preparedness, ready to do battle against an unpredictable menace that may strike in any place at any time. Hellboy's lack of malice and self-interestedness identifies him with the ethos of G2s [military intelligence officers] fighting a just war against Fascism as opposed to US involvement in a morally and politically questionable war in Iraq. And his laconic can-do attitude offers a welcome antidote to the ineffectual bureaucratization of home security. (O'Connor 561).

While O'Connor sees Hellboy's phenomenally powerful right hand as concretizing an "ethical dilemma" and quotes a Mignola interview where he likened it to nuclear power which, when "used correctly, it's great, but in the wrong hands, it's the most devastating thing there is" (O'Connor 560), it is also Hellboy's monstrous appearance that plays a slightly twisted role in protecting the State. This monstrousness is a vehicle of fantasy, but it also suggests the dehumanization of war.

23Tony M. Vinci's analysis of the Hellboy II movie shows how the franchise inscribes itself in several variations of fantasy (Vinci 1041). Whereas Hellboy II is closer to Tolkien's fantasy rather than the more abysmal Lovecraftian model, the first Hellboy film as well as the comic books manifest Lovecraftian "cosmic horror" instead of elaborate fantasy. Taking off from Rosemary Jackson's interpretation of Frankenstein's otherness as representing "the intricacy of our psychological understanding of the human," Vinci argues that "representations of otherness in fantasy narratives not only embody psychological perspectives but often represent cultural forces and ideologies. In this way, Hellboy becomes a representative of the "normal" American, influenced heavily by Western ideology..." (Vinci 1043). Although Vinci sees the psychological, cultural and ideological construction of the Other as an outcome of our “"postcontemporary' present" (Vinci 1043), it is perfectly feasible to extend these categories to otherness in general. Shakespeare's Caliban, Othello and Shylock are ideal examples of the molding of Others through cultural as well as political perceptions and beliefs. Hellboy's ambiguity comes in through his being partly the self, the character readers usually identify with, as well as the monster, or the Other.

24All the issues published after 9/11 (i.e. after Conqueror Worm) feature Hellboy going solo in an increasingly uncontrollable fantasy world culminating a decade later (in The Storm and the Fury) in a world that is destroyed but with hope of reconstitution. A sense of foreboding is already evident in Conqueror Worm, opening with Edgar A. Poe's eponymous poem, which concludes with the following stanzas replete with rich imagery of inevitable doom:

A blood-red thing that writhes from out

The scenic solitude!

It writhes!-it writhes!-with mortal pangs

The mimes become its food, 
And the seraphs sob at vermin fangs

In human gore imbued.

[...] the play is the tragedy, "Man,"

And its hero the Conqueror Worm. (Poe).

25These stanzas also play on the ambiguity within Hellboy, for he is both the "bloodred thing," the hero of the tragedy as well as the man in it. At end of the series, when he dies battling Nimue who becomes the dragon or beast of the Apocalypse, he reenacts the monk's story from The Right Hand of Doom, who sacrificed his life killing a dragon and whose spilled blood left a wake of lilies.

26Guillermo del Toro, who directed and wrote the two Hellboy movies (which are not direct adaptations of the Hellboy comics), followed Mignola (see his introduction to the short story "Third Places" in Strange Places) in turning to fantasy for Pan's Labyrinth in the wake of 9/11. Del Toro explained that after 9/11 "whatever I had to say about brutality and innocence had just changed" (Kermode and Del Toro). In Pan's Labyrinth (just like in The Orphanage and The Devil's Backbone before), Del Toro wanted to show "that the only real monsters are human" (Kermode Del Toro). Yet after 9/11 he felt the need to merge the genre of horror with fantasy. Fantasy offered the possibility of distance, transposition and reconstruction of a reality gone horrifically out of hand, just like it did for Tolkien, who had fought in one world war and was writing The Lord of the Rings during the second one. Although the hope offered by fantasy is always individualistic, internal, exemplifying the power of the imagination to escape through mental constructions, those constructions, no matter how fantastic, are inevitably extracted from reality. Their very presence during a time of collective shock reflects the magnitude of that shock and the need to sublimate the trauma. This could explain why Del Toro's Hellboy movies also incorporate increasing degrees of fantasy with Hellboy II: The Golden Army, released in 2008 but made around the same time as Pan's Labyrinth, decidedly succumbing to the endangered fairy tale world of Prince Nuada, the last of the warrior elves trying to preserve the magical races by waging war against humankind, as described by Vinci below:

Nuada enters Hellboy's life in the form of a myth or fairy tale. In his opening sentence to The Uses of Enchantment, Bruno Bettelheim argues that "if we hope to live not just from moment to moment, but in true consciousness of our existence, then our greatest need and most difficult achievement is to find meaning in our lives" (3), and fairy tales can help us accomplish this. They "stimulate [the] imagination; help [us] to develop [the] intellect and to clarify [our] emotions; to be attuned to [our] anxieties and aspirations; give full recognition to [our] difficulties," ultimately inspiring the "inner resources" required to antagonize cultural norms and ideologies (Bettelheim 5). I contend that this is precisely how the story of Nuada affects Hellboy, and perhaps the viewer. It offers him the "wishes, dreams, and needs which have been denied by social structures and institutions" (Zipes 190). In this way, Hellboy represents the viewer, caught in between the "evil" humans depicted in the film and Hellboy, the "normal guy" who may be inspired to stop aspiring to the status quo. (Vinci 1055)

27 Whereas Vinci emphasizes the effects of the fairy tale on Hellboy in the Hellboy II film, the yielding to fantasy and reflection on the readers' reality is also discernible in the conflicted Hellboy of the comics, especially if one takes 9/11 into account. According to O'Connor, "[t]he moral ambiguity represented by Hellboy's Right Hand of Doom resonates with cultural anxieties about terrorist assaults and fear that the United States itself may wreak destruction upon the world" (O'Connor 561). Thus The Right Hand of Doom, with its allusion to the potential of the country's destruction from within, 
through its own hand as it were, reflects national insecurities. The Hand of Doom harbors within it not only a considerable degree of uncertainty similar to a nuclear weapon that could go off any second, but also an ambiguity of the kind described by Dittmer for the post-9/11 Captain America comics, where Captain America starts questioning America's role in training the terrorists working against it (Dittmer 640-641).

28 After The Conqueror Worm, Hellboy leaves the BPRD and in the $12^{\text {th }}$ volume from 2011 dies trying to save England (and the world) by proving that he is not the legendary sleeping King Arthur. The Conqueror Worm was published before 9/11 and the general increase in nationalistic sentiment that it provoked. Nonetheless in the remaining seven volumes, Hellboy steers more or less clear of the New World, although he does remain American in attitude and language and even talks of returning to in The Storm and the Fury. During this self-imposed exile, Hellboy remains largely cut-off from human contact, socializing essentially with the supernatural, particularly the dead. Ultimately it is the fantastic in the form of Nimue who transforms herself into a dragon that eventually kills Hellboy but leaves a bunch of lilies, rich in Christian symbolism (Virgin Mary, Christ's Resurrection), amidst the debris. Hence contrary to what Ursula Le Guin held almost 50 years ago in her essay on "Why Are Americans Afraid of Dragons," Americans might be more open to dragons and other myths than ever before because of the trauma of a century marred by overseas wars and the recent threats infiltrating, for the first time since its independence, its own borders.

\section{Hellboy as self-reflection on comics}

29The third strand of interpretation focuses on Hellboy's interaction with the medium of comics. This begins with a discussion of how the series manifests tendencies that appear to be ensconced in comics. It then explores possible connections between Hellboy'sparodying, or more accurately, self-reflexive, playful interaction with the sociopolitical history of the comics medium. These elements are self-reflexive in that they challenge the precepts of the Comics Code, in a manner similar to the way in which the main character rebels against his prescribed destiny. The first version of the Comics Code was established in 1954 to regulate comics productions in light of charges of corrupting young readers. The Code resulted in the end of many popular comics series, such as the horror comics of EC. The Comics Code was revised two times (in 1971 and 1989), gradually losing its influence by the time of the second revision (see CBLDF).

30The ambiguity introduced by Hellboy in the interpretations of American identity and defense exemplifies comics' inclination towards caricature, the visualization of irreverence, and the possibility of liberation through laughter, much in the vein of the Rabelaisian world of the carnivalesque (Sommers 226-227). Sommers describes Hellboy as "couched in a sort of parodic discourse, both valorizing and quietly mocking, of the narratives that inspired it" (Sommers 224). Going in a similar direction as Sommers but attempting to provide a theoretical grounding, Ole Frahm suggests that comics are composed of "weird signs" that in themselves parody "the common notion of how signs and reality, signs and reference relate" (Frahm 177). Yet this seems to be less of a given of the medium itself (there are, after all, comics that do not engage in parody) and more of a treasured tradition, which Hellboy does adhere to, especially when one reconsiders it through some of the stipulations of the comics' censorship introduced in 
the 1950s. Although the rules themselves have been shelved, they continue to reflect the binaries of good and bad upheld even today. This binary is in part rejected by Hellboy.

31 Using the measuring rod of "good taste," the Comics Code Authority's list from 1954 banishes "lurid, unsavory, gruesome illustrations" as well as "[s]cenes dealing with, or instruments associated with walking dead, torture, vampires and vampirism, ghouls, cannibalism, and werewolfism" (Part B, Items 3 and 5). Hellboy's efforts to contain and destroy demons and other supernatural beings under the aegis of the US government is thus pertinent on the figurative level when one considers the first Comic Code's restrictions. The same code also stipulates that "Policemen, judges, Government officials and respected institutions shall never be presented in such a way as to create disrespect for established authority" (Part A, Item 3 - a comparable requirement is maintained in the otherwise far less proscriptive Comics Code Revision of 1989). Yet Hellboy does leave the BPRD before half of the series is over and also harbors misgivings and resentment regarding government and military institutions trying to control the activities of the BPRD and maintain a difference between its human and non-human agents. This becomes uncomfortably obvious in Conqueror Worm, where Roger is implanted with a "fail-safe device" or a bomb, which the official in response to Hellboy's retorts says would never be put on Liz Sherman because she is human, even though she had also inadvertently killed a few people and was therefore as big a threat as Roger. This is probably one of the major reasons behind Hellboy's resignation, with another one being the death of Lobster Johnson, who remains ignored, deemed nonexistent and hence considered just as expendable as Roger or any other non-human, including Hellboy himself. While Lobster Johnson could be metonymic for the many failed and forgotten comic book heroes, he is also belittled just as the comics medium itself was looked down upon.

32 Another precept of the Comics Code insisting that "good shall triumph over evil and the criminal punished for his misdeeds" (Part A, item 6) is nullified, and not merely rejected in Hellboy through the protagonist's death, which shows that he was unable to continue fighting his destiny as an apocalyptic creature and that the many evil enemies he made were ultimately the end of him. In other words, Hellboy could not continue on the side of the good, nor could good unfailingly triumph (at least not without a Pyrrhic victory). Finally his very existence as simultaneously monstrous and human unsettles the traditional notions of good and bad in a manner comparable but not tied to the hybridity of comics.

\section{Coloring the imaginaries of individual and State through Hellboy}

33More than incorporating ambiguity, Hellboy like most pop cultural products is a mélange of disparate but familiar ingredients, an appropriation and transformation enabled by globalization. Although they should be taken with more than a grain of salt, cultural products like comics, with their tendencies of amalgamation, can provide pertinent reflections on the sociopolitical context of their creation. Hellboy is no Captain America, even though Captain America changed after 9/11, but he is the conflicted hero of a post-Watchmen world, who embraces the fantastic after $9 / 11$ as a means of sublimating its shock. Nonetheless Hellboy's biggest conflict remains an 
internal one between destiny and will. His story therefore indirectly filters the individualism and the protestant work ethic forming the cornerstone of the subliminal ideologies crucial for the American Dream while problematizing nationalistic conceptions through adding the element of monstrosity or otherness. These allusions to the sociopolitical milieu, veiled by completely impossible figures and events, in turn are characteristic of the genre Hellboy is closest to, fantasy. Yet while playing out on supernatural and individual levels, Hellboy does not completely sidestep the selfcriticism that the War on Terror provoked. Indeed, the very placement of a demon in the US defense structure, even if it is essentially a good demon, while hinting at the problem of integrating immigrants and the perpetuation of human war machines, also inserts unease regarding the construction of the country's enemies, for Hellboy and the monsters he fights by share the same origin in the paranormal and remain inextricably linked. With fantasy ultimately emerging as the dominant genre of the series whose monstrous hero can only lessen, but not completely avert, the impending destruction, a parallel with the destruction continuing in our ongoing reality is hard to ignore.

34 Hence, on one level Hellboy can be read as enveloping, through the sheen of fantasy, the problem of integrating others and demarcating the enemy as well as exemplifying the scope of State protection and its dependence on identity constructions. On another level it does what comics seem to do so well and with considerable eagerness: portray identity issues, include some tongue-in-cheek ambiguity and self-reflection and pack it all in gripping tales, flamboyantly merging genres and worlds.

\section{BIBLIOGRAPHY}

Bukatman, Scott. The Poetics of Slumberland. Animated Spirits and the Animating Spirit. Chicago: Chicago UP, 2012. Print.

CBLDF (The Comic Book Legal Defense Fund). “The Comics Code of 1954.” 29 Mar. 2013 <http:// cbldf.org/the-comics-code-of-1954/>. Web.

CBLDF. “Comics Code Revision of 1989.” 29 Mar. 2013 <http://cbldf.org/comics-code-revisionof-1989/>. Web.

Dittmer, Jason. “Captain America's Empire: Reflections on Identity, Popular Culture, and Post-9/11 Geographies." Annals of the Association of American Geographers 95.3 (2003): 626-643. Print.

Frahm, Ole. "Weird Signs. Comics as Means of Parody." Comics and Culture: Analytical and Theoretical Approaches to Comics. Eds. Anne Magnussen and Hans-Christian Christiansen. Copenhagen: Museum Tusculanum Press, 2000.177-191. Print.

Freese, Peter. "American National Identity in a Globalized World as a Topic in the Advanced EFLClassroom.” American Studies Journal 51 (2008) 25 Mar. 2013 <http://www.asjournal.org/ archive/51/103.html>. Web. 
Genter, Robert. "“"With Great Power Comes Great Responsibility." Cold War Culture and the Birth of Marvel Comics." The Journal of Popular Culture 40.6 (2007): 953-978. Print.

Grant, Susan-Mary. "Raising the Dead: War, Memory and American National Identity." Nations and Nationalism 11.4 (2005): 509-529. Print.

Hellboy. Dir. Guillermo del Toro. Revolution Studios, 2004. DVD.

Hellboy II: The Golden Army. Dir. Guillermo del Toro. Universal Pictures, 2008. DVD.

Kermode, Mark and Guillermo del Toro. "Guardian/ NFT Interview: Guillermo del Toro". The Guardian. (21 Nov. 2006) 31 Mar. 2013.

<http://www.guardian.co.uk/film/2006/nov/21/guardianinterviewsatbfisouthbank>. Web.

Johnson, Jeffrey J. Super-history: Comic Book Superheroes and American Society, 1938 to the Present. Jefferson, NC: McFarland, 2012. Print.

Le Guin, Ursula K. “Why Are Americans Afraid of Dragons?” PNLA Quarterly 38 (1974): 14-18. Print.

Lund, Martin. "American Golem: Reading America Through Super-New Dealers and the "Melting Pot"." Comic Books and American Cultural History: An Anthology. Ed. Matthew Pustz. New York, NY: Continuum, 2012. 79-93. Print.

Mignola, Mike. Hellboy: The Conqueror Worm. Milwaukie, OR: Dark Horse Books, 2002

(unpaginated). Print.

Mignola, Mike and John Byrne. Hellboy: Seed of Destruction. Milwaukie, OR: Dark Horse, 2003 (unpaginated). Print.

Mignola, Mike. Hellboy: Le Cerceuil Enchainé. Paris: Delcourt, 2003. Print.

Mignola, Mike. Hellboy: The Right Hand of Doom. Milwaukie, OR: Dark Horse, 2003 (unpaginated). Print.

Mignola, Mike, Hellboy: Strange Places, Milwaukie, OR: Dark Horse, 2006 (unpaginated). Print.

Mignola, Mike and Duncan Fredo. Hellboy: The Storm and the Fury. Milwaukie, OR: Dark Horse Books, 2012 (unpaginated). Print.

Murray, Christopher. "Holy Hypertexts! - the Pose of Post-modernity in Comics and Graphic Novels of the 1980". Reflections on Creativity. Ed. Hamid van Koten. Dundee: Duncan of Jordanstone College of Art and Design, 2007. 28 Mar. 2013

<http://artanddesign.dundee.ac.uk/reflections/pdfs/ChrisMurray.pdf>. Web.

Murrin, John M. “A Roof Without Walls: The Dilemma of American National Identity.” 25. Mar. 2013 <http://academic.brooklyn.cuny.edu/history/burrows/AmRev/Documents/Murrin.htm>. Web.

O'Connor, Laura. “The Corpse on Hellboy's Back: Translating a Graphic Image.” The Journal of Popular Culture 43.3 (2010): 540-563. Print.

Poe, Edgar Allan. “The Conqueror Worm.” Poetry Foundation. 30 Mar. 2013 <http:// www.poetryfoundation.org/poem/178359>. Web.

Smolderen, Thierry. Naissances de la bande dessinée. De William Hogarth à Winsor McCay. Brussels: Les Impressions Nouvelles, 2009. Print. 
Sommers, Joseph Michael. "Crooked Appalachia: The Laughter of the Melungeon Witches in Hellboy: The Crooked Man." Comics and the U.S. South. Ed. Brannon Costello and Qiana J. Whitted. Jackson, MS: UP of Mississippi, 2012. 214-241. Print.

Vinci, Tony M. "Remembering Why We Once Feared the Dark: Reclaiming Humanity Through Fantasy in Guillermo del Toro's Hellboy II.” The Journal of Popular Culture 45.5 (2012): 1041-1059. Print.

Weiner, Stephen, Jason Hall, and Victoria Blake (with additional material by Mike Mignola). Hellboy. The Companion. Milwaukie, OR: Dark Horse Books, 2008. Print.

\section{ABSTRACTS}

This article explores possible implications of the Hellboy comic book series for constructions of individual and national identity in the American context, accounting for the factors of globalization and 9/11 as well as precedents in the comics medium. It also considers Hellboy as a self-reflection on the history and nature of the comics medium itself.

\section{INDEX}

Keywords: 9/11, Comics/ graphic novels, fantasy, identity

Mots-clés: Christopher Murray, Edgar Allan Poe, Erik H. Erikson, Guillermo del Toro, H. P. Lovecraft, Hector St. John de Crevecoeur, Jason Dittmer, Jeffrey J. Johnson, John Byrne, John M. Murrin, John Trumbull, Joseph Michael Sommers, Laura O'Connor, Martin Lund, Max Weber, Mike Mignola, Ole Frahm, Peter Freese, Robert Genter, Stephen Weiner, Susan-Mary Grant, Tony M. Vinci, Ursula K. Le Guin

\section{AUTHOR}

\section{MAAHEEN AHMED}

Université catholique de Louvain 